\title{
PRIMARY TUBERCULOSIS IN AFRICAN CHILDREN
}

\author{
BY \\ F. STEPHEN CARTER \\ From King George VI Hospital, Nairobi, Kenya Colony
}

(RECEIVED FOR PUBLICATION DECEMBER 9, 1953)

The patients who comprise the clinical material for this investigation were all African children admitted to the medical wards of King George VI Hospital during the period August, 1952, to September, 1953, inclusive. Most of the children were Wakikuyu ( $78 \%$ ) and came from the native reserves or from the African locations in Nairobi. It has been found impossible to divide them into rural and urban groups owing to the large number of accommodation and fictitious addresses given by the parents. It is known that a considerable proportion of those who gave a Nairobi address had in fact come from the reserves a few days previously.

It was an established routine that every child on admission to hospital had a Mantoux test performed, the site of injection being examined at 48 hours and thereafter daily for a further three days. The injection consisted of $0.1 \mathrm{ml}$. of 1 in 1,000 old tuberculin (Burroughs Wellcome), the solution being freshly prepared in the Medical Research Laboratory, Nairobi. The diluting fluid used during the period of this investigation was $0.5 \%$ carbol saline. It is often difficult to detect an erythematous reaction in the darkly pigmented skin of an African, and in this series the presence of palpable induration of the skin was used to determine positive reactors.

In cases where the reaction was in doubt, and in those patients who were suspected of having tuberculosis but were negative reactors, the test was repeated using a 1 in 100 dilution.

In all, 1,149 consecutive children were tested and the results are shown in Table 1. All children who died or left hospital within 48 hours have been excluded from this investigation.

In this series there were 131 positive reactors and a further 31 patients who had active tuberculosis but were negative reactors to both 1 in 1,000 and 1 in 100 dilutions of old tuberculin. These latter have been recorded as 'false negatives'. Every patient with a false negative reaction was found to have rapidly progressive disease, and in most cases they were suffering from an advanced stage of the disease at the time of admission. All this group of
TABLE 1

RESULTS OF MANTOUX TESTS ON 1,149 AFRICAN CHILDREN

\begin{tabular}{c|c|c|c|c}
\hline $\begin{array}{c}\text { Age in } \\
\text { Years }\end{array}$ & $\begin{array}{c}\text { No. of } \\
\text { Cases }\end{array}$ & $\begin{array}{c}\text { No. of } \\
\text { Positive } \\
\text { Reactors }\end{array}$ & $\begin{array}{c}\text { No. of } \\
\text { False } \\
\text { Negative } \\
\text { Reactors }\end{array}$ & $\begin{array}{c}\text { Total Positive } \\
\text { and False } \\
\text { Negative } \\
\text { Reactors (\%) }\end{array}$ \\
\hline Under 1 & 345 & 16 & 4 & $5 \cdot 8$ \\
$1-2$ & 214 & 14 & 7 & $9 \cdot 8$ \\
$2-3$ & 191 & 16 & 6 & $11 \cdot 5$ \\
$3-4$ & 153 & 20 & 4 & $15 \cdot 7$ \\
$4-6$ & 144 & 26 & 6 & $22 \cdot 2$ \\
$6-8$ & 71 & 23 & 2 & $35 \cdot 2$ \\
$8-10$ & 31 & 16 & 2 & $58 \cdot 1$ \\
\hline
\end{tabular}

patients died, the majority within 10 days of entering hospital, and the longest period of survival recorded following a false negative reaction was four weeks.

Among the 131 positive reactors there were 18 children $(13.7 \%)$ who showed a hypersensitive reaction to the 1 in 1,000 Mantoux test. In these children, the site of the injection showed vesiculation at 48 hours, which led to ulceration, the lesion usually being a half to one inch in diameter. No particular age group was affected, but 17 out of the 18 cases showed evidence of an active lesion.

Of 162 infants and children who were either positive or false negative reactors, 132 (101 positives and 31 false negatives) were investigated with a view to assessing the activity or quiescence of the disease. Whenever possible each child had a radiograph taken of the chest, an examination of the sputum or gastric washings for tubercle bacilli, and a sedimentation rate (Westergren) estimation, in addition to routine charting of weight and temperature. The results obtained are shown in Table 2 .

TABLE 2

ASSESSMENT OF ACTIVE TUBERCULOSIS IN MANTOUXPOSITIVE AND FALSE-NEGATIVE REACTORS

\begin{tabular}{|c|c|c|c|}
\hline $\begin{array}{l}\text { Age in } \\
\text { Years }\end{array}$ & $\begin{array}{c}\text { No. of } \\
\text { Cases }\end{array}$ & $\begin{array}{l}\text { No. with Active } \\
\text { Tuberculosis }\end{array}$ & $\begin{array}{l}\text { No. with Quiescent } \\
\text { Tuberculosis }\end{array}$ \\
\hline $\begin{array}{c}\text { Under } 1 \\
1-2 \\
2-3 \\
3-4 \\
4-6 \\
6-8 \\
8-10\end{array}$ & $\begin{array}{l}16 \\
21 \\
22 \\
16 \\
24 \\
24 \\
13\end{array}$ & 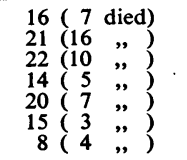 & $\begin{array}{l}\text { Nil } \\
\text { Nil } \\
\text { Nil } \\
2 \text { (both doubtful) } \\
4 \text { (one doubtful) } \\
9 \text { (one doubtful) } \\
5\end{array}$ \\
\hline
\end{tabular}


Nine children are included in Table 2 who were taken out of hospital by their parents, but whose condition was deteriorating so rapidly that their expectation of life could not reasonably have been expected to exceed a week. (It has been assumed that these children died.)

It seems likely that the death rate in the under1-year-old group may be artificially low. The mothers of these infants were admitted as well as their infants in order that breast feeding might be maintained. Several mothers discharged themselves and their infants prematurely before the outcome of the infection could be determined.

The very high mortality rate during the second and third years of life is probably due to a great extent to the very poor standard of nutrition which is general in this age group among African children. Kwashiorkor and other nutritional diseases in particular occur in this section of the population, as the children are deprived of many of the basic necessities of life. Infants over 1 year old have to learn to fend for themselves as their mothers are often occupied with a more recent addition to the family. The state of emaciation and semi-starvation of these young children provides little resistance to infection with the tubercle bacillus, and they succumb to the disease very readily.

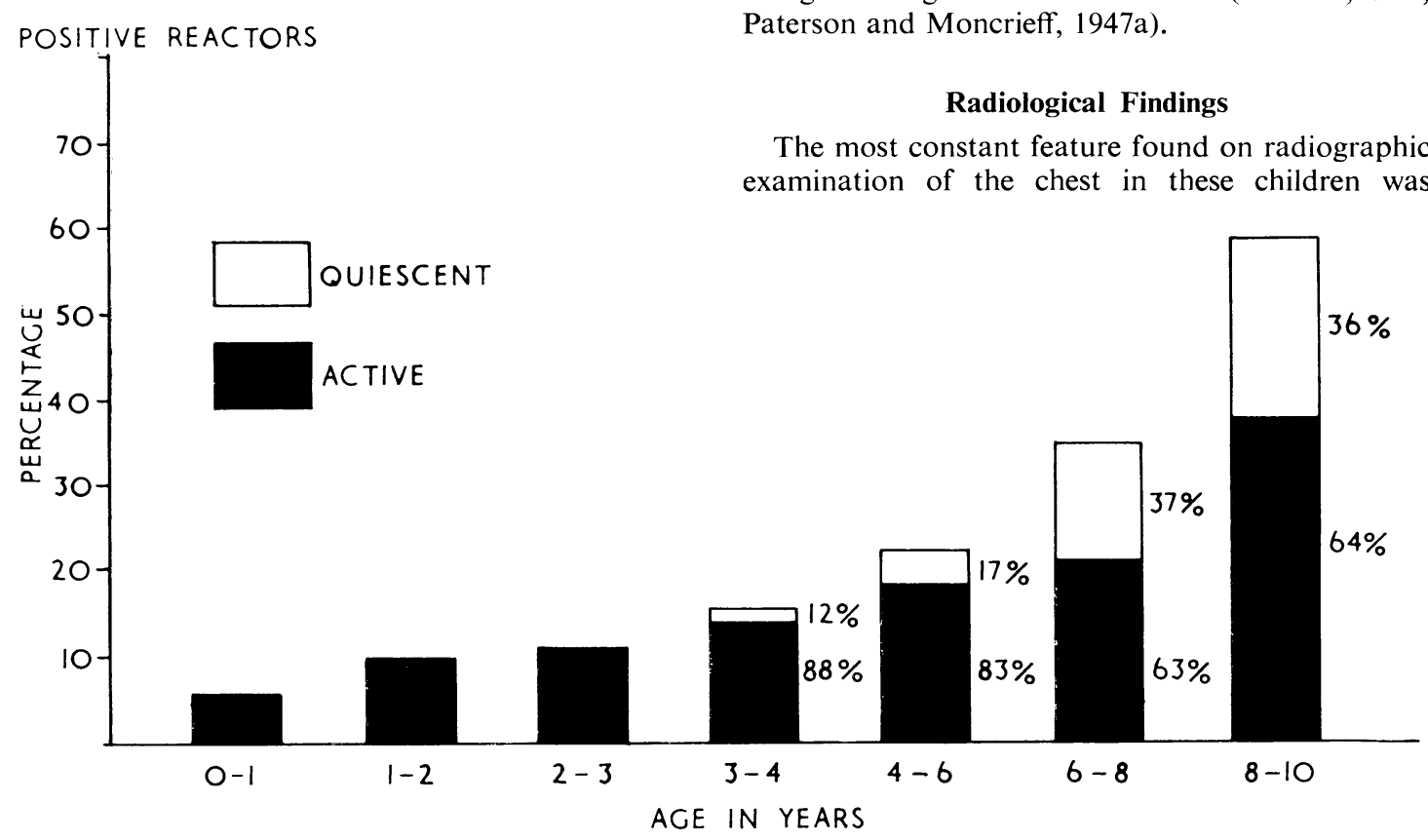

The clinical features of children with active primary tuberculosis show certain differences from those found in European children. Forty-one children, selected as having active primary lesions, have been kept under observation in hospital and as out-patients during the last 15 months. It is hoped that a preliminary report will be published shortly on the natural history of primary tuberculosis in the African child in Kenya, based on these selected cases.

Several of these children were discovered as a result of showing a positive reaction to the tuberculin test, and if this had been omitted there would have been no reason to suspect an active primary infection as there were no symptoms suggestive of the disease. Most of the children, however, appeared ill, the commonest symptoms being lassitude and mental apathy, combined with fever, a harsh, dry cough, anorexia and loss of weight.

Fever was a particularly prominent symptom. In 14 patients $\left(34_{0}^{\circ}\right)$ the temperature on admission was in excess of $102^{\circ} \mathrm{F}$., and usually remittent in character. There were only 10 patients $(24 \%)$ in the series whose temperature remained persistently below $100^{\circ} \mathrm{F}$. The degree of pyrexia appears to be considerably greater than that found in children in the United Kingdom, where there is usually only a low-grade irregular fever of 99 to $100^{\circ}$ (Sheldon, 1943; Paterson and Moncrieff, 1947a).

\section{The most constant feature found on radiographic} examination of the chest in these children was

FIG. 1.-The incidence of active tuberculosis among tuberculin reactors. 
enlargement of the hilar glands. This was present in $40(97 \cdot 5 \%)$ out of 41 patients, and the glandular enlargement was of a very considerable degree in 24 $(58.5 \%)$ of them. It may be suggested that as these children were selected patients they might have been selected on account of the enlarged hilar glands, thereby raising the proportion of patients with glandular enlargement. The selection of cases, however, depended on the patients being free from other disease, which, by its nature, might interfere with the natural progress of the tubercular lesion. For this reason one patient was removed from the series on account of typhoid fever, which would have invalidated the temperature chart, if nothing else. During the course of the investigation all children were accepted as suitable provided there was no evidence of the development of a tuberculous bronchopneumonia, miliary spread or tuberculous meningitis when the child was examined initially. On a number of occasions children were tentatively accepted for inclusion in the series on account of a positive tuberculin test and an otherwise unexplained fever before a radiograph had been taken.

Opacities extending out from the root of the lung were also frequently encountered. These lesions, previously described as epituberculous, but more recently considered to be due to absorption collapse (Graham and Hutchison, 1947) or collapse-consolidation (Adler and Richards, 1953), were present to a varying degree in 28 patients $(68 \%)$. Table 3 shows the distribution of these opacities, which were all either segmental or lobar in extent.

TABLE 3

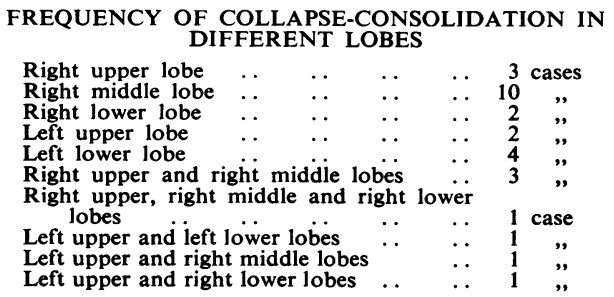

In this series, of 34 lobes involved, the right middle lobe was affected on 15 occasions, the right upper, left upper and left lower lobes on five occasions each, and the right lower lobe four times.

\section{Mode of Death}

In those patients who succumbed to the disease, death usually occurred within three months of the first symptom referable to a tuberculous infection, and this is in agreement with the views of Wallgren (1938) and Paterson and Moncrieff (1947b).

In a series of 47 consecutive deaths from tuber- culosis among children, the cause of death, as diagnosed on clinical and radiological grounds, was as shown in Table 4.

\section{TABLE 4}

CAUSE OF DEATH IN 47 TUBERCULOUS CHILDREN Tuberculous bronchopneumonia $\quad$. . . 29 cases

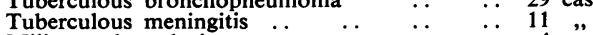

$\begin{array}{llllll}\text { Muberculous meningitis } & \ldots & \ldots & \ldots & \ldots & 11 \\ \text { Miliary tuberculosis } & \ldots & \ldots & \ldots & \ldots & 4\end{array}$

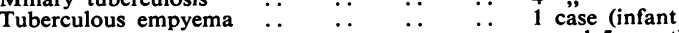

Tuberculous pericarditis with completely caseous left lower lobe

Tuberculous bronchopneumonia of left lung with large cavity in left upper lobe

1 case (infant aged 1 year)

1 case (infant aged 8 months)

Necropsies were performed on 10 of the patients dying from tuberculous bronchopneumonia, and of these, six were found to have miliary spread which had not been diagnosed during life. In each case, however, it was apparent that the dissemination was of recent origin. Tubercles were most numerous in the liver and spleen, the kidneys having to be examined with care to demonstrate lesions macroscopically. In one of these cases, the miliary spread was of such recent onset that only three tubercles were seen on the surface of the liver, and a very occasional lesion was found on cutting sections through the liver substance. No tubercles were found in either spleen or kidneys in this patient.

Four of the patients dying from tuberculous meningitis were examined at necropsy. In two of them, the only other signs of tuberculosis were enlarged caseating hilar glands, and the other two showed widespread miliary tuberculosis.

Death caused primarily by miliary tuberculosis occurred on only four occasions, and the diagnosis was made radiologically in each instance. This is a very much lower incidence than was found by Graham-Johnstone (1949a) working in the same hospital. In her series of 87 positive reactors in children under 6 years old, 16 patients showed radiological evidence of miliary dissemination and 22 showed exudative or pneumonic lesions. It is possible that the variation may be due to individual differences in interpretation of the radiographs, as it was noticed on several occasions in the present series that a rapidly progressive bronchopneumonia produced numerous, fine, and widespread opacities scattered throughout the lung fields, giving a picture very similar to that of miliary tuberculosis.

Cammock and Miller (1951), in their study of tuberculosis in young children in Newcastle, note that tuberculous meningitis and miliary tuberculosis are the major immediate hazards of primary tuberculosis. It is apparent that tuberculous bronchopneumonia is of much greater importance in Kenya among African children than it is among children in the United Kingdom. 
TABLE 5

AGE INCIDENCE IN YEARS AND PRIMARY CAUSE OF DEATH IN 47 TUBERCULOUS CHILDREN

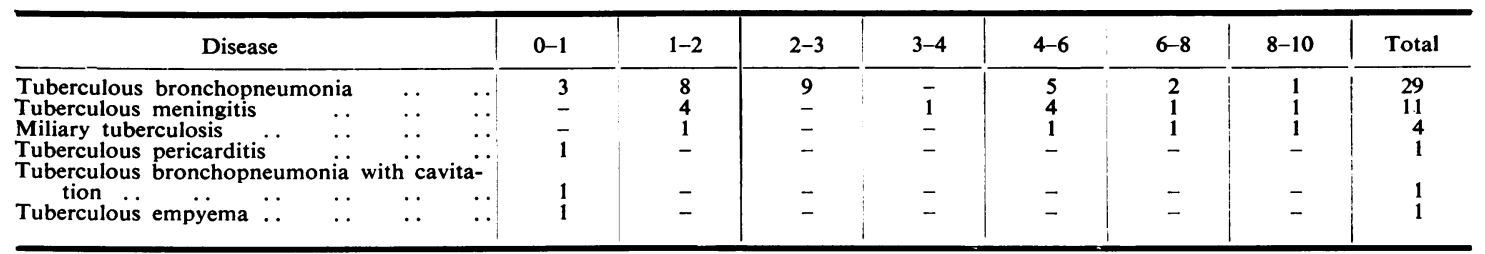

(All children included in Table 5 were either seen in consultation or were directly under the care of the author. A number of deaths recorded in Table 2 are not included.)

\section{Discussion}

Mantoux Reaction and Primary Tuberculosis. Biggs (1946) considered primary tuberculosis to be a subclinical disease in that a diagnosis could not be made by a general clinical examination, and that height and weight charts were of no assistance. He came to the conclusion that skin testing with tuberculin was the only efficient way to detect the disease, and that its course should be followed by serial radiographs. Many authors have pointed out the value of the Mantoux intradermal and Vollmer patch tests as an indication of previous infection with the tubercle bacillus, but the tests by themselves do not indicate how recently the infection was acquired and they are of little guidance as to the activity of the disease. Several authors, including Ansell and Soltys (1950), consider that marked reactions favour, but do not prove, active disease. This is in agreement with the findings in the present investigation, where 17 out of 18 patients showing a hypersensitive reaction were proved to have active disease. Graham-Johnstone (1949a) and Haynes (1951a) came to the conclusion that the site of the lesion had a direct bearing on the degree of sensitivity shown by the tuberculin test. The highest percentage of hypersensitive reactors occurred among patients suffering from glandular tuberculosis, and tuberculous lesions of bone were the next most frequent, while pulmonary tuberculosis produced the lowest hypersensitivity rate.

Graham-Johnstone (1949b) tested the tuberculin reactions of 800 infants and children under the age of 6 years at the same hospital in Nairobi, and obtained results very similar to the present investigation. There were 87 positive reactors and six with false negative reactions, giving a combined figure of $11.6 \%$ compared with $11.4 \%$ in this series. Haynes (1951b), during a survey of tuberculosis in Kenya, tuberculin tested 328 children under 6 years in three different centres in Nairobi, and found $28(8 \cdot 6 \%)$ positive reactors. These figures are not strictly comparable as one group was drawn from an urban area, and the others were selected groups in that all the children were admitted to hospital. They also differ in that the children came from rural as well as urban districts.

The reactor rate to tuberculin among children admitted to hospital has been investigated by Fleming (1943), who reported that in The Royal Hospital for Sick Children, Glasgow, there were $9.3 \%$ positive reactors in children under 4 years, $26.3 \%$ in the $4-7$-year-old group, and $38.1 \%$ in children from 7 to 10 years old. Stewart (1947) in Australia carried out a similar investigation among children admitted to the Perth Children's Hospital. He found a reactor rate of $5 \%$ during the second year of life, $20 \%$ in the fourth year, $44 \%$ in the ninth year and $51 \%$ in the thirteenth year. He concluded that the children were being exposed to an abnormal risk of infection, and probably excessively frequently. It appears that a large number of cases in Perth were due to bovine tuberculosis, as Margolis (1951), in repeating the investigation in the same hospital a few years later, showed a considerable fall in the reactor rate, which he considered to be due to the slaughtering of all dairy cattle found to have positive tuberculin reactions in the period between the two investigations. In the Nairobi area bovine tuberculosis is rare. Ginsberg (1953) reports that of 10,838 head of cattle slaughtered in the abattoir at Athi since it was opened in July, 1953, only six have been found affected with tuberculosis.

Myers, Harrington and Garcia Suarez (1945) pointed out that wherever large numbers of contagious cases of tuberculosis are permitted to exist among people or animals without adequate isolation or control, a high percentage of children develop primary tuberculosis. Haynes (1951c) has drawn attention to the higher rate of tuberculin reactors among African adults in urban populations in Kenya compared with those of rural districts, and came to the conclusion that a significant number underwent their primary infection in adult life on coming to work in the towns from the native reserves.

The younger the child, the greater the likelihood 
there is that a positive tuberculin test will indicate active disease. Opie (1947) quoted Mourad as stating that in infants under 1 year a positive reaction is invariably associated with active tuberculosis, and that during the second year $88 \%$ show clinical evidence of the disease falling to $81 \%$ during the third year. Kayne, Pagel and O'Shaughnessy (1948) considered that a child under 2 years with a positive test should be regarded as having a progressive lesion, but from 2 to 5 years the lesion could no longer be regarded as necessarily active. In those over 5 years and in adults they considered that a positive reaction merely indicated that the patient had undergone a tuberculous infection at some period in the past. Similar conclusions were drawn by Ansell and Soltys (1950).

Considerable variation in the incidence of active disease in the same age groups occurs in different parts of the country. At the Royal Aberdeen Hospital for Sick Children, Clark (1951) found evidence of active infection in $56 \%$ of city children and $40 \%$ of country children under 6 years who were admitted to hospital, but Ounsted and Smallpeice (1951), working in the Children's Department of the United Oxford Hospitals, produced evidence that $80.8 \%$ of positive reactors among children of 3 to 7 years old attending hospital had active tuberculosis. They considered that the activity rate fell sharply after the age of 7 years as only $27.9 \%$ in the 7-14-year-old group showed active lesions. They drew attention to the fact that variations occurred in the activity rate from place to place, and advised that each district should review its own area in order to assess the problems of treatment and control required.

Radiological Evidence of Primary Tuberculosis. Enlargement of the hilar and mediastinal glands occurred in a very high percentage of the children selected for observation as having active primary lesions. Haynes (1951d), in examining radiographs of 43 children with tuberculosis, found hilar glands enlarged in $30(69.8 \%)$ patients. The patients were not selected in the same manner as in the present investigation, but confirm the opinion that such glandular enlargement is a prominent feature in primary tuberculosis among Africans in this Colony. The occurrence of glandular enlargement appears to vary throughout the world. There is a high incidence among American Indian children (High and Zwerling, 1946), but among positive reactors in children in Minneapolis radiographic examination revealed evidence of significant disease so rarely that its use among young children was discontinued (Myers, 1946). This is in contrast to the findings in Kenya, where radiographic examination of the chest has been found to be a valuable aid to diagnosis.

Segmental and lobar opacities involved the right middle lobe much more frequently than any other lobe, and similar observations were made by Richards (1944) and Brock (1950). Richards found the right middle lobe involved in 23 out of 66 affected lobes, and 60 out of 93 were involved in the series published by Brock, who explained the reason for this preponderance on anatomical grounds. First, the middle lobe bronchus is smaller than those supplying the other lobes and therefore more easily compressible, and secondly, the gland usually responsible for causing obstruction to the middle lobe bronchus drains the right lower lobe as well as the middle lobe, which may thus become enlarged as a result of infection from two different sources.

Mortality Rate. The mortality rate among children with tuberculosis admitted to King George VI Hospital was extremely high, particularly in children under 3 years (see Table 2).

Although the number of cases is comparatively small and can have no statistical significance, the general trend indicates that primary tuberculosis in the African child in Kenya carries with it a fearsome mortality rate. Some of the children included in Table 2 were admitted in a very advanced state of the disease, and it may be criticized that the figures are biased, giving an unduly high death rate. It is, however, frequently quoted that patients who have a collapsed segment or lobe of a lung due to pressure on a bronchus or occlusion by caseous material from the rupture of a gland into a bronchus, have a very favourable prognosis (Graham and Hutchison, 1947). In this series, of 28 patients showing such radiological changes, two developed tuberculous meningitis and two died from tuberculous bronchopneumonia, giving a mortality rate of over $14 \%$.

The onset of tuberculous bronchopneumonia was usually followed by rapid deterioration, death often ensuing within two or three weeks and sometimes within a few days. The rupture of a caseating gland into a bronchus leads to dissemination of tuberculous pus along the bronchial tree. The associated obstruction of the bronchus causes absorption collapse or collapse-consolidation, but the lack of immunity among African children often fails to localize the lesion and the disease extends to bronchopneumonia with a fatal termination. In those races which have acquired immunity the usual course of the disease following the stage of collapse is either complete resolution or residual collapse, which may be associated in either case with bronchial 
stenosis and a symptomless bronchiectasis (Veeneklaas, 1952). Tuberculous bronchopneumonia is an infrequent complication of the primary lesion.

In Kenya, however, apart from coastal areas, tuberculosis has been introduced comparatively recently (Haynes, 1951e), and the native population has developed little immunity, with the consequence that fulminating exudative and pneumonic lesions are common sequelae of the primary infection in childhood.

The incidence of tuberculosis among children in England has fallen steadily since the beginning of this century, and Wolman (1952) points out that the chief cause is the fall in the morbidity rate among adults, who are the principal source of infection. This has been due to 'improved measures of prevention, greater care of patients, increased education of the public and a change for the better in the general social and economic conditions of the country'. He found that of 20 children aged 4 years who were positive reactors to tuberculin, the source of infection in 17 was found to be due to direct family contact.

The same principles for the protection of children from tuberculosis apply in Kenya. It must be stressed once again that the adult patient with open tuberculosis in the home is the greatest danger to the child, and efforts to control the disease must aim at the early diagnosis and removal of infectious patients from close contact with uninfected people. The standards of housing and hygiene among the native population are distressingly low in many areas. Much is being done in the Colony to raise these standards. Some of the recommendations put forward by Haynes (1951f) have been implemented. It is hoped that the investigation of B.C.G. vaccination among native children will prove it to be a valuable contribution in the prevention of the disease. The control of the disease, however, rests to a great extent on the degree of cooperation obtained from the Africans themselves and their response to the increasing efforts that are being made to raise their standards of personal hygiene and social welfare.

A satisfactory degree of control of tuberculosis in the Colony cannot be envisaged for many years to come.

\section{Summary}

The results are given of Mantoux tests performed on 1,149 consecutive African children admitted to King George VI Hospital, Nairobi. There were 131 positive reactors and 31 false negatives. All children with false negative reactions died.

All positive reactors under 3 years old ( 59 patients) were found to have active tuberculosis; the activity rate among children of 4 to 6 years was $83 \%$ and $62.5 \%$ among those of 6 to 8 years.

Fever was a prominent feature among those with active primary tuberculosis. In 14 out of 41 patients the temperature on admission was above $102^{\circ} \mathrm{F}$.

Enlargement of the hilar or mediastinal glands was an almost constant radiological feature and was gross in $24(58 \cdot 5 \%)$ patients.

Opacities in the lung fields of an 'epituberculous' nature were present in $28(68 \%)$ patients, the right middle lobe being involved on 15 occasions.

The mortality rate among the younger children was extremely high, rising to $76 \%$ during the second year. Tuberculous bronchopneumonia was the most frequent cause of death, occurring in 29 out of 47 tubercular deaths. Miliary tuberculosis occurred as a primary cause of death four times, but was found to an unimportant extent at necropsy on a number of occasions. Tuberculous meningitis occurred 11 times.

Primary tuberculosis among African children in Kenya carries with it a much less favourable prognosis than is found among races which have developed immunity. It is considered that the frequency of tuberculous bronchopneumonia is an indication of the lack of immunity among the native population.

I am indebted to the Hon. the Director of Medical Services, Kenya, for permission to publish this paper. I should like to thank Dr. Lorna Macdougall for her cooperation and for giving me access to her patients. My thanks are also due to Miss M. Marshall and many other ward sisters who gave valuable assistance in carrying out this investigation. Miss P. M. Allen, Librarian at the Medical Research Laboratory, Nairobi, has rendered much help in the study of the literature.

\section{REFERENCES}

Adler, D. and Richards, W. F. (1953). Thorax, 8, 223.

Ansell, I. and Soltys, M. A. (1950). Practitioner, 165, 265.

Biggs, A. D. (1946). Arch. intern. Med., 77, 393.

Brock, R. C. (1950). Thorax, 5, 5.

Cammock, R. M. and Miller, F. J.

Clark, N. S. (1951). Ibid., 2, 464.

Ginsberg, A. (1953). Personal communication.

Graham, Stanley and Hutchison, James H. (1947). Archives of Disease in Childhood, $22,162$.

Graham-Johnstone, Mary (1949a). Unpublished work, quoted by Haynes (1951), p. 96.

Haynes (1951), p. 96.
(1949b). Ibid., p. 94.

Haynes, W. S. (195ia). Tuberculosis in Kenya, p. 130. Nairobi.

(1951b). Ibid., p. 81 .

(1951c). Ibid., p. 109.

(1951d). Ibid., p. 124

(1951e). Ibid., p. 103 .

High (1951f). Ibid., p. 137. 61, 1769 .

Kayne, G. G., Pagel, W. and O'Shaughnessy, L. (1948). Pulmonary Tuberculosis, 2nd ed., p. 291 . London.

Margolis, J. (1951). Med. J. Aust., 1, 433.

Myers, J. A. (1946). Publ. Hlth. Rep., Wash., 61, 1563.

-, Harrington, F. E. and Garcia Suarez, E. (1945). J. Amer. med. Ass., 128, 852 . 
Opie, W. H. (1947). S. Afr. med. J., 21, 740.

Ounsted, C. and Smallpeice, V. (1951). Brit. med. J., 2, 1437.

Paterson, Donald and Moncrieff, Alan (1947a). Garrod, Batten and Thursfield's Diseases of Children, 4th ed., vol. 1, p. 663. London.

Rich (1947b). Ibid., vol. 1, p. 664

Richards, W. F. (1944). Proc. roy. Soc. Med., 37, 589.
Sheldon, Wilfrid (1943). Diseases of Infancy and Childhood, 4th ed., p. 383. London.

Stewart, V. A. Fergusson (1947). Med. J. Aust. 1,46

Veeneklaas, G. M. H. (1952). Amer. J. Dis. Child., 83, 271.

Wallgren, A. (1938). Lancet, 1, 417.

Wolman, B. (1952). Brit. J.'Tuberc., 46, 24. 